\title{
Campilobacteriose genital bovina: ocorrência nos estados do Rio de Janeiro e Minas Gerais
}

\section{Genital bovine campilobacteriosis: occurrence in Rio de Janeiro and Minas Gerais states}

\author{
Vera Lúcia Teixeira de Jesus, * José Eugênio Trés, * Júlio Cesar Ferraz Jacob, * \\ Lisiane Burgos Leite Mendoza Latorre, ${ }^{* \star}$ Juracy de Castro Borba Santos Júnior**
}

\section{Resumo}

Para verificar a ocorrência de campilobacteriose genital bovina, em rebanhos de bovinos leiteiros do Rio de Janeiro e Minas Gerais, realizou-se a prova de muco-aglutinação lenta para as fêmeas, e o isolamento bacteriológico para os machos. Dos 248 animais examinados durante o período de 1996 a dezembro 1997, constataram-se 71 animais positivos $(28,63 \%)$, 33 suspeitos $(13,31 \%)$ e 144 negativos $(58,06 \%)$, provenientes de 21 propriedades visitadas nos estados do Rio de Janeiro e Minas Gerais, sendo diagnosticada a campilobacteriose em 20 propriedades $(95,2 \%)$. A campilobacteriose provavelmente contribuiu para a baixa eficiência reprodutiva verificada nos rebanhos examinados.

Palavras-chave: Campilobacteriose genital; diagnóstico; ocorrência.

\section{Introdução}

O Campylobacter fetus subsp. venerealis (Smith, Taylor, 1919) é um agente infeccioso de importância sanitária devido aos prejuízos econômicos que pode causar ao rebanho infectado, como repetições de cios, aumento do período do ciclo estral para 27 a 51 dias, morte embrionária, aborto, retenção de placenta e, conseqüentemente, a esterilidade enzoótica das fêmeas infectadas.

O hábitat natural de $C$. fetus subsp. venerealis, na fêmea infectada, é a mucosa vaginal, da cérvix, do útero e da tuba uterina, ocorrendo produção de anticorpos em resposta a infecção, que podem ser evidenciados através do teste de muco-aglutinação cérvico-vaginal. No macho, a campilobacteriose não induz à formação de anticorpos, suficiente para a utilização como meio de diagnóstico e aparece com mais freqüência em touros mais velhos (idade de quatro a oito anos), possivelmente pelo tamanho das criptas epiteliais no prepúcio (Clark, 1971).

Os resultados dos diagnósticos laboratoriais ainda são insatisfatórios, sendo que o método mais empregado para fêmeas é o teste de muco-aglutinação lenta, tendo a desvantagem de ocorrerem falsos negativos ou positivos. Contudo, pode ser recomendado como prova de rotina para avaliação da doença no rebanho (Eaglesome, Garcia,
1992). Para a colheita do muco cérvico-vaginal, segue-se a técnica descrita por Laing (1960).

Para os machos, o método e diagnóstico empregado é o isolamento bacteriológico, que possui o inconveniente da contaminação inicial do esmegma prepucial, e a exigência de $C$. fetus subsp. venerealis de microaerofilia (Ramos et al., 1987). O material para esse exame pode ser obtido através de swab prepucial (Gibson et al., 1970), pipeta plástica de inseminação acoplada a um bulbo plástico (Bartlett et al., 1947) e por meio de lavado prepucial (Mello, 1953), devendo o touro estar em repouso sexual por, pelo menos, uma semana antes da colheita (Genovez et al., 1986).

Os meios de cultivo de eleição, indicados para o transporte e cultivo do material para o diagnóstico da campilobacteriose, em machos são os de Neill (Neill et al., 1980) e de Reed e Orr (Fontelles, 1993).

A imunofluorescência direta pode ser utilizada para o diagnóstico de $C$. fetus subesp. venerealls com resultados semelhantes ao do isolamento bacteriológico (Leite, 1977 ; Pellegrin et al., 1998).

A prevalência da campilobacteriose nos rebanhos é elevada, como verificado por alguns autores, em vários estados do Brasil: no Rio Grande do Sul, em $27 \%$ das fazendas

\footnotetext{
* Departamento Reprodução e Avaliação Animal, Instituto de Zootecnia, Universidade Federal Rural do Rio de Janeiro (UFRRJ), Km 47 da Antiga Rodovia Rio-São Paulo, 23851 -970, Seropédica, RJ, Brasil.

**Aluna do Curso de Graduação em Medicina Veterinária, Instituto de Veterinária, UFRRJ, Seropédica, RJ, Brasil.

${ }^{\star \star \star}$ Faculdade de Veterinária, Fundação Educacional D. André Arcoverde, Valença, RJ, Brasil.
} 
examinadas (Mies Filho, 1960) e no Rio de Janeiro, em $72 \%$ dos rebanhos (Guida, Langenegger, 1989). Em outros países, como na Argentina, Vilar e Spina (1992), encontraram $22 \%$ de rebanhos positivos através do teste de imunofluorescência direta em lavados prepuciais. McCool et al. (1988), na Austrália, encontraram a prevalência de $87 \%$ em rebanhos de gado de corte.

Devido à importância desta doença e sua elevada prevalência nos rebanhos bovinos, buscou-se estudar a ocorrência em rebanhos dos estados do Rio de Janeiro e Minas Gerais.

\section{Materiais e métodos}

As colheitas das amostras para diagnóstico de $C$. fetus subsp. venerealis foram realizadas no período de março de 1996 a dezembro de 1997, pela equipe do Laboratório de Patologia da Reprodução (LPR) do Projeto Saúde Animal, do convênio EMBRAPA / UFFRJ.

Os animais estudados eram provenientes de 21 propiedades, de 14 municípios, dos estados do Rio de Janeiro e Minas Gerais, com histórico de repetição de cio, aborto por volta do sexto mês de gestação, retenção de placenta e metrites. As propriedades utilizavam monta natural associado com inseminação artificial, os quais estão representados na Tabela 1.

Tabela 1: Distribuição das fazendas atendidas pela equipe do LPR (Convênio EMBRAPA/UFRRJ) nos estados do Rio de Janeiro e Minas gerais, para o diagnóstico de campilobacteriose bovina

\begin{tabular}{ccc}
\hline Estados & Municípios visitados & Fazendas atendidas \\
\hline & Angra dos Reis & 1 \\
& Barra Mansa & 1 \\
& Barra do Piraí & 1 \\
Rio de Janeiro & Nova Iguaçu & 1 \\
& Paty de Alferes & 1 \\
& Rio das Flores & 3 \\
& Seropédica & 3 \\
& Valença & 2 \\
& Vassouras & 1 \\
& & \\
& Rio Preto & 2 \\
Minas Gerais & Santa Bárbara & 1 \\
& Simão Pereira & 1 \\
& Três Corações & 1 \\
& Varginha & 2 \\
\hline
\end{tabular}

Foram utilizados 248 animais, sendo 46 reprodutores machos e 202 fêmeas, provenientes de rebanhos leiteiros, com diferentes graus de sangue, oriundos de cruzamen- tos da raça Holandesa com a Gir, representados na Tabela 2 .

Tabela 2: Distribuição dos 248 animais examinados para campilobacteriose genital bovina, nos estados do Rio de Janeiro e Minas Gerais em 1996 e 1997.

\begin{tabular}{cccc}
\hline Estados & Machos & Fêmeas & Total \\
\hline Rio de Janeiro & 40 & 170 & 210 \\
Minas Gerais & 06 & 32 & 38 \\
\hline Total & 46 & 202 & 248 \\
\hline
\end{tabular}

Todos os touros em serviço e $10 \%$ das fêmeas em reprodução, escolhidas ao acaso, foram utilizados para colheita de material, sendo a colheita de muco vaginal das fêmeas feita segundo recomendação de Laing (1960) e a do esmegma prepucial nos machos pela técnica de Bartlett et al. (1947), com acondicionamento do material em meios de transporte e cultivo de Neill, composto por Leptospira EMJH ${ }^{1}$, 5-Fluorouracil, soro de coelho, agar, sendo confeccionado no setor de meio de cultivo do LPR (Neill et al., 1980) e meio Reed \& Orr também confeccionado no LPR, composto por Peptona, Cloreto de Sódio, Tiogliocolato de Sódio ${ }^{2}$ e Agar (Fontelles, 1993). Tanto o material colhido das fêmeas como o dos machos foram acondicionados em gelo e enviado ao laboratório.

No laboratório, o muco vaginal foi submetido à prova de muco-aglutinação lenta para o diagnóstico de campilobacteriose, seguindo a técnica descrita por Laing (1960), utilizando antígeno, obtido de culturas de $C$. fetus subsp. venerealis, mantidas no LPR.

O esmegma prepucial, acondicionado nos meios de transporte, foi incubado por 24 horas, a $37^{\circ} \mathrm{C}$, sendo realizado o exame bacteriológico e a leitura para identificação morfológica, tintorial e bioquímica das prováveis colônias de $C$. fetus subsp. venerealis segundo critérios estabelecidos pelo Manual Bergey's (1994).

Os dados obtidos foram submetidos à análise estatística, pelo teste $Z$, para verificar a diferença entre proporções dos animais positivos nos dois estados estudados.

\section{Resultados e discussão}

Quanto ao diagnóstico da campilobacteriose bovina, dos 46 reprodutores submetidos ao exame bacteriológico do esmegma prepucial, encontrou-se $18(39,1 \%)$ positivos e $28(60,9 \%)$ negativos, dados estes que estão representados na Tabela 3.

\footnotetext{
1 EMJH Leptospira enrichment supplement (DIFCO).

2 Tioglicolato de sódio para microbiologia (MERCK).
} 
Tabela 3: Resultados obtidos nos 46 touros submetidos ao isolamento bacteriológico para campilobacteriose genital bovina, nos meios Neill e Reed \& Orr, nos estados do Rio de Janeiro e Minas Gerais em 1996 e 1997

\begin{tabular}{cccc}
\hline Estados & Positivos & Negativos & Total \\
\hline Rio de Janeiro & $17(42,5 \%)$ & $23(57,5 \%)$ & 40 \\
Minas Gerais & $01(16,7 \%)$ & $05(83,3 \%)$ & 06 \\
\hline Total & $18(39,1 \%)$ & $28(60,9 \%)$ & 46 \\
\hline
\end{tabular}

Na Tabela 4, são representados os resultados obtidos nas 202 fêmeas bovinas, submetidas à prova de mucoaglutinação lenta, para diagnóstico de aglutininas antiCampylobacter fetus, tendo sido encontradas 53 fêmeas positivas $(26,3 \%), 33$ suspeitas $(16,3 \%)$ e 116 negativas $(57,4 \%)$.

Tabela 4: Resultados obtidos nas 202 fêmeas bovinas através da prova de muco-aglutinação lenta para diagnóstico de aglutininas anti- $C$. fetus, nos estados do Rio de Janeiro e Minas Gerais em 1996 e 1997

\begin{tabular}{ccccc}
\hline Estados & Positivas & Suspeitas & Negativas & Total \\
\hline Rio de Janeiro & $38(22,3 \%)$ & $26(15,3 \%)$ & $106(62,3 \%)$ & 170 \\
Minas Gerais & $15(46,9 \%)$ & $07(21,9 \%)$ & $10(31,2 \%)$ & 32 \\
\hline Total & $53(26,3 \%)$ & $33(16,3 \%)$ & $116(57,4 \%)$ & 202 \\
\hline
\end{tabular}

Quando se confrontaram os números de machos positivos observados nos estados do Rio de Janeiro e Minas Gerais, não foi encontrada diferença significativa $(Z=1,22<$ $1,96)$. Porém precisa ser levado em consideração o reduzido número de machos avaliados no estado de Minas Gerais, possivelmente devido a descarte de reprodutores com problemas reprodutivos.

Houve diferença altamente significativa entre os números de fêmeas positivas nos dois estados $(Z=2,89>2,58)$, verificando-se maior ocorrência no estado de Minas Gerais.
Das 21 propriedades atendidas, foi constatada a ocorrência de C. fetussubsp. venerealis em $20(95,2 \%)$ fazendas, sendo esta taxa superior às encontradas por Guida e Langenegger (1989), no Rio de Janeiro, e por Vilar e Spina (1992) na Argentina, que foi de $22,0 \%$.

Os resultados encontrados de $71(28,63 \%)$ animais positivos, entre fêmeas e machos, de um total de 248 e a identificação de $95,2 \%$ de fazendas com animais contaminados, confirma que os métodos de colheitas e isolamentos foram satisfatórios para se verificar a doença nos rebanhos estudados, como sugerido por Eaglesome e Garcia (1992).

O elevado número de fazendas que mostraram animais positivos para $C$. fetus subsp. venerealis, pode ser explicado pelo fato deste estudo ter sido conduzido em propriedades com histórico de infertilidade, demostrando a importância desta doença na eficiência reprodutiva do rebanho.

Visto que existem disponíveis formas de controle estabelecidas e adotadas desde da década de 50 como relatado por Clark (1971), como a vacinação, o tratamento com antibiótico e lavado prepucial em touros, descanso reprodutivos para as fêmeas e adoção exclusiva da inseminação artificial, a alta ocorrência da doença demonstra o manejo inadequado nas fazendas, por desconhecimento sobre o assunto, devido à falta ou falha de assistência técnica adequada.

\section{Conclusões}

Apesar dos estudos disponíveis produzidos pelas instituições de ensino e pesquisa, ainda se verifica uma ocorrência elevada de campilobacteriose genital bovina nos rebanhos bovinos leiteiros, comprometendo a fertilidade do rebanho.

Faz-se necessária a realização de levantamentos epidemiológicos mais completos e abrangentes para que se possa obter informações sobre a real situação da campilobacteriose genital bovina e se estabeleça estratégias de controle sanitário integrado desta doença, nas diversas microrregiões fisiográficas dos estados estudados.

\begin{abstract}
To verify the occurrence of genital bovine campilobacteriosis in dairy cattle in Rio de Janeiro and Minas Gerias, it was realized a slow mucus agglutination test for the females and bacteriologic isolation for the males. From the 248 examined animals during the period of 1996 to december 1997 , it was diagnosed 71 positive animals (28.63\%), 33 suspect (13.31\%) and 144 negatives (58.06\%) representing 21 visited proprieties in Rio de Janeiro and Minas Gerais States, and Campilobacteriosis has been diagnosed on 20 proprieties (95.2\%). The Campilobacteriosis probably help to get a low reproductive efficience, verified in studied cattle.
\end{abstract}

Keywords: Genital Campilobacteriosis; diagnostic; occurrence. 


\section{Referências bibliográficas}

BARTLETT, D. E., HASSON, E. V., TEETER, K. G. Ocurrence of Trichomonas fetus in preputial samples from infected bulls. J.A.V.M.A, v. 110, p. 114-120, 1947.

BERGEY'S. Manual of Determinative Bacteriology, 9. ed., Baltimore, Maryland : USA, Willians \& Willians, 787 p., 1994.

CLARK, .B.L. Review of bovine vibriosis. Aust Vet. J, v. 47, n. 3, p. 103-107, 1971.

EAGLESOME, M. D., GARCIA, M. M. Microbial agents associated with bovine genital tract. Vet Bull., v. 62, n. 8, p. 743-775, 1992.

FONTELLES, A. L. B. Comparação de meios de cultivo na manutenção dos agentes da tricomonose e da campilobacteriose. Tese de Mestrado, UFRRJ, Seropédica/ RJ, 63 p., 1993.

GENOVEZ, M. E., SCARCELLI., E., PICONE, A. B. B. Avaliação de dois métodos de coleta de muco prepucial no diagnóstico da campilobacteriose genital em touros. Biol, v. 52, n. 1/3, p. 7-11, 1986.

GIBSON, H. A., DREHER, W. H., ZEMJANIS, R. Simplified technique for collection of preputial samples from bulls for isolation of Vibrio fetus . J.A.V.M.A., v. 157, p. 834-836, 1970.

GUIDA, H. G., LANGENEGGER, J. Doenças infecciosas da reprodução reduzem produtividade do rebanho leiteiro. Gado Holandês, v. 54, n. 160, p. 36-38, 1989.

LAING, J.A. La Vibriosis Genital de los Bovinos. FAO: Estudos Agropecuários, n. 51, 67 p., 1960.
LEITE, R. C. Avaliação de alguns métodos de diagnóstico e análise custo $x$ benefício do controle da campilobacteriose bovina. Tese de Mestrado, UFMG, Belo Horizonte, 38 p., 1977.

McCOOL, M. P.; TOWNSEND, M. P.; WOLFE, S. G. Prevalence of bovine venereal disease in Victoria River District of the Northen Territory likely economic effects and praticable control measures. Aust. Vet. J., v. 65, n. 5, p. 153-156, 1988.

MELLO, M. E. Meio prático para diagnóstico da tricomonose bovina. Bol. Soc Med. Vet, v. 21, p. 11-19, 1953.

MIES FILHO, A. Incidência de vibriose bovina em alguns rebanhos leiteiros no Rio Grande do Sul. Rev. Fac. Agron. Vet, v. 3, p. 195-199, 1960.

NEILL S.D., O'BRIEN, I. J., ELLIS, W. A. The isolation of aerotolerant Campylobacter. Vet. Rec, v.106, p. 152-153, 1980.

PELLEGRIN, A. O., SERENO, J. R. B., LEITE R. C. et al. Campilobacteriose genital bovina em touros do Mato Grosso do Sul. Rev Bras Rep Anim, v. 22, n. 1, p. 43-47, 1998.

RAMOS, A. A., GUIDA, H.G., ANDRADE, V. L. B. Meio de cultura com e sem antibiótico e filtro millipore no isolamento de $C$. fetus de reprodutores bovinos infectados naturalmente. Hora Vet., v. 7, n. 37 , p. 40-46, 1987.

SMITH, T., TAYLOR, M. S. Some morphological and biological characters or the Spirilla (Vibrio fetus) associated with disease of fetal membranes in cattle. J. Exp. Med., v. 30, p. 299-311, 1919.

VILAR, J. A., SPINA, B. M. Campilobacterioses (Vibriosis) Bovina: una recopilación de datos sobre su incidencia en el período 1966-1981. Gac Vet., v. 44 , n. 372, p. 647-658, 1982. 